\title{
Finish line for full coverage crown: A systematic review
}

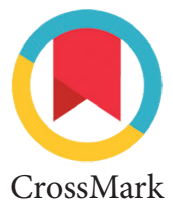

\author{
Eri H. Jubhari, ${ }^{*}$ Edwina Lesal
}

\begin{abstract}
Objective: To find the mostly used type of finish line for each types of full coverage crown.

Methods: An initial search was conducted from PubMed database and Wiley Online Library to evaluate article about finish line and material types of full coverage crown. The keywords used were "finish line" and "fixed prosthodontics". The initial results of this search were 175 articles. Preferred Reporting Items for Systematic reviews and MetaAnalysis (PRISMA) guidelines and Population/Problem, Intervention, Comparison/Control, and Outcome (PICO) questions were used for manual selection. After manual selection, there were only 4 articles
\end{abstract}

that met the inclusion criteria, focusing on the number of each type of materials for full coverage crown.

Results: From these 4 articles, two were in vivo study and another two were in vitro study, with a total samples 140 . The samples used in those articles were all-ceramic, all-metal, and zirconia crowns. Two articles did not mention about instrument (bur) and only 3 articles mention about impression materials.

Conclusion: In all-metal and all-ceramic crown articles, chamfer finish line were mostly used, but, in zirconia crown article, both rounded shoulder and shoulder-less/knife-edge were equally used.
Department of Prosthodontic, Faculty of Dentistry, Hasanuddin University, Makassar, Indonesia
*Correspondence to:

Eri H. Jubhari, Department of Prosthodontic, Faculty of Dentistry, Hasanuddin University, Makassar, Indonesia erijubhari@gmail.com

Received: 16 July 2018 Revised: 31 July 2018 Accepted: 10 August 2019 Available Online: 1 April 2021

Keywords: Finish line, Fixed prosthodontics, Crowns

Cite this Article: Jubhari EH, Lesal E. 2021. Finish line for full coverage crown: A systematic review. Journal of Dentomaxillofacial Science 6(1): 1-4. D0I: 10.15562/jdmfs.v6i1.775

\section{Introduction}

An adequate and accurate tooth preparation is important for marginal fit in fixed prosthodontics. ${ }^{1}$ One of the most important stages in determining the success of fixed prosthodontics is the preparation of the finish line. Because of this preparation at the confluence between the edges of the restorations with the supporting tooth tissues. ${ }^{2}$ A bad restoration margin will damage adjacent structure regardless of the restoration type. A well-adapted crown will decrease bacteria plaque accumulation. ${ }^{3}$ Therefore, many types of finish line have been recommended for different types of material for fixed prosthodontics crown to maximize the esthetics feature, and to minimize irregularities and stress concentration at the margins. ${ }^{1}$ Full coverage crown are usually suggested by clinicians to restore the teeth for its esthetic and functional properties, such as major caries or fractured cusp. ${ }^{4,5}$ Restoring teeth require sufficient space based on the material that will be used in fixed prosthodontics. ${ }^{6}$

Conventionally, dental abutment was prepared until there is finish line created where the restoration rests. The crown margin can be located subgingivally or supragingivally. But the subgingival margin rarely used because it will lead to gingival inflammation. Finish line can be classified into two main groups namely horizontal, such as the curved chamfer, flat chamfer and straight shoulder, and vertical, such as feather or knifeedge margins. ${ }^{6,7}$ Nowadays, many patients prefer restoration in full coverage crown than partial coverage crown. Meanwhile, so many clinicians, especially the fresh graduate dentist, who did not really understand the design and use of each finish line in tooth preparation as an initial step for making a full coverage crown.

This systematic review was carry out to look for the most used type of finish line for each type of material of the full coverage crown.

\section{Methods}

Preferred Reporting Items for Systematic reviews and Meta-Analysis (PRISMA) guidelines were used in this article. ${ }^{8}$ In this systematic article, Population/Problem, Intervention, Comparison/Control, and Outcome (PICO) questions were "any teeth that will be prepared to restore the teeth structure with full coverage crown and assess the type of finish line that more suitable for each type of material type for full coverage crown."

\section{Search Strategy}

An initial search was conducted from PubMed database and Wiley Online 


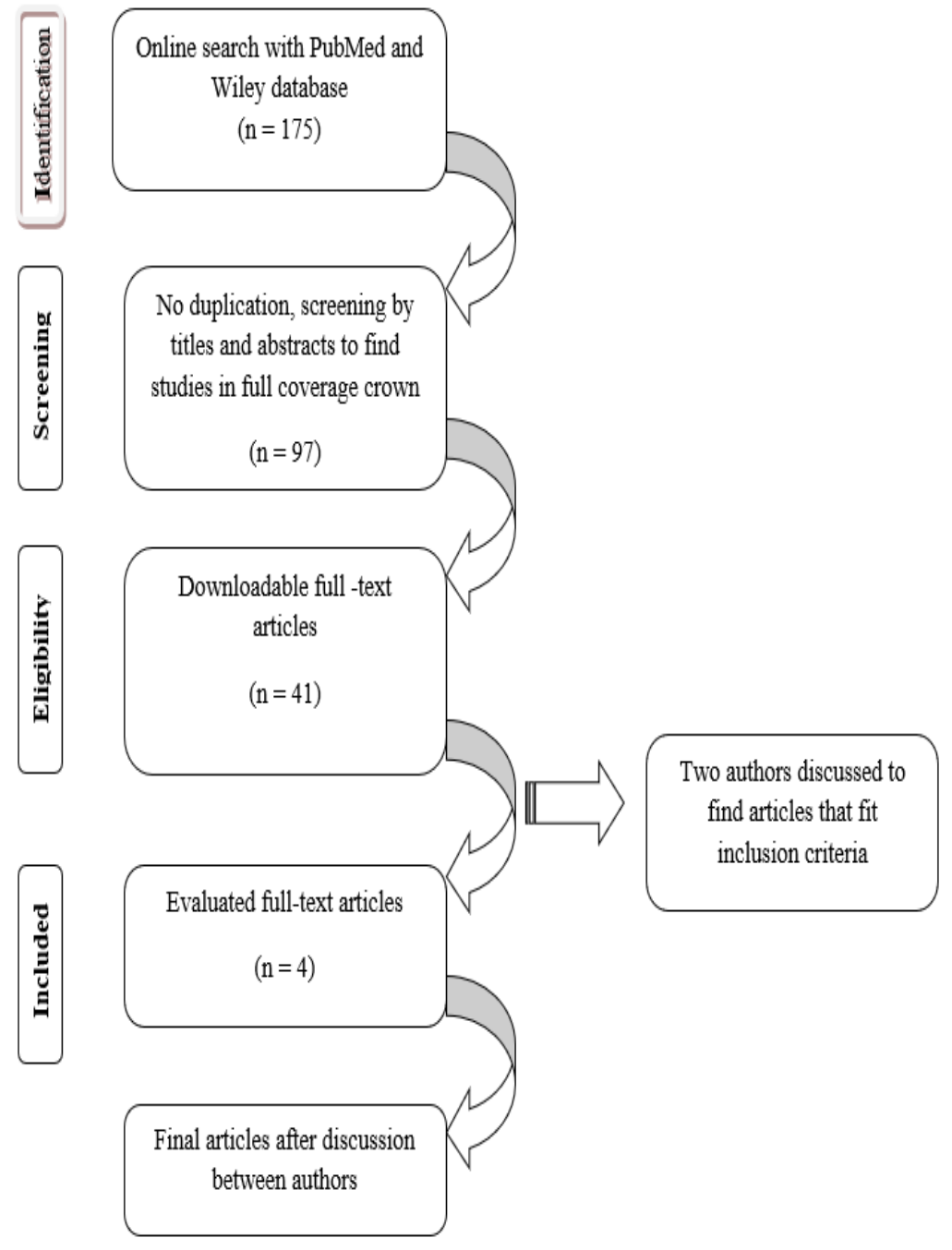

Figure 1 PRISMA Flow Chart specific keywords. The authors selected independently articles to find articles that compatible with the inclusion criteria. Each article were selected carefully by screening the title, and reviewing the abstract, methods, and results. After that, the authors listed the final articles that would be used in this study.

\section{Extraction of Data}

The data that compatible with inclusion criteria were listed by two reviewers until the final articles were obtained. Data from the selected articles that will be used in this systematic review were name of the authors, year of publication, subjects, material types of full coverage crown and their finish lines.

\section{Results}

In initial search by two authors, there were 175 articles found. After screening the titles, reviewing the abstracts and full-text, 171 articles were excluded because 69 articles were not studies in full coverage crown, 9 articles were about systematic review or meta-analysis or literature review, 38 articles were studies in partial prosthodontics or implants or not a full coverage crown, 20 articles were not full-text articles, 15 articles were not mention about material types of full coverage crown or finish line, or both of them and 20 articles were studies in models.

From 4 articles that were included in this review, number of samples used in those articles were 46 in Vigolo et al. ${ }^{9}$ article, 30 in Akin et al..$^{10}$ article, 4 in Taha et al. ${ }^{11}$ article and 60 in Tsiagali et al. ${ }^{12}$ article, with total sample were 140 .

Table 1 showed two articles conducting an in vivo study and two other articles were using in vitro study. The studies conducted by Akin et al. ${ }^{10}$ and Taha et al. ${ }^{11}$ were using all-ceramic crown material, but they are using different finish line: chamfer finish line in Akin et al. ${ }^{10}$ study and shoulder finish line in Taha et al. ${ }^{11}$ study. In zirconia material study, Vigolo et al. ${ }^{9}$ were comparing two different finish line: rounded shoulder and shoulder-less (knifeedge). And for all-metal material study, Tsiagali et al. ${ }^{4}$ were using chamfer finish line.

The inclusion criteria in this systematic review were articles in English, the subjects were human teeth, any kind of finish line preparation, and the articles were published between January 2015 to December 2017. On the other hand, all articles with models as subject, articles about implant, removable and fixed partial denture, also systematic review and meta-analysis or literature review and not a fulltext article were excluded.

\section{Selection of Article}

The authors of this article used unique and

\section{Discussion}

The study that were done by Akin et al. ${ }^{10}$ used all-ceramic crown with chamfer finish line. They were usually used the all-ceramic crown in maxillary anterior region because of the esthetics and natural appearance. For a successful esthetic result, the finish line of tooth preparation at the cervical area should be approximately $0.5 \mathrm{~mm}$ below the free gingival crest. According to Shillingburg et al. ${ }^{13}$ a 


\begin{tabular}{|c|c|c|c|c|c|c|c|}
\hline \multirow{2}{*}{ Author } & \multirow{2}{*}{ Type of study } & \multirow{2}{*}{ Samples } & \multicolumn{3}{|c|}{ Type of Materials for Full Coverage } & \multirow{2}{*}{$\begin{array}{c}\text { Instrument } \\
\text { (Bur) }\end{array}$} & \multirow{2}{*}{$\begin{array}{l}\text { Impression } \\
\text { Material }\end{array}$} \\
\hline & & & All-Metal & All-Ceramics & Zirconia & & \\
\hline Vigolo et al & In Vivo Study & 46 & - & - & $\begin{array}{l}23 \text { Rounded- } \\
\text { shoulder } \\
23 \text { Shoulder-less } \\
\text { (knife-edge) }\end{array}$ & No mentioned & $\begin{array}{c}\text { Impregum Penta; 3M } \\
\text { ESPE, Seefeld, } \\
\text { Germany } \\
\text { Irreversible } \\
\text { hydrocolloid }\end{array}$ \\
\hline Akin et al & In Vivo Study & 30 & - & Chamfer & - & $\begin{array}{l}\text { Fine diamond bur } \\
\text { (856EFO12; Komet, } \\
\text { Lemgo, Germany) }\end{array}$ & $\begin{array}{l}\text { Polyvinylsiloxane } \\
\text { Irreversible } \\
\text { hydrocolloid }\end{array}$ \\
\hline Taha et al & In Vivo Study & 4 & - & Shoulder & - & No mentioned & No mentioned \\
\hline Tsiagali et al & In Vivo Study & 60 & Chamfer & - & - & $\begin{array}{l}8 \mathrm{~mm} \text { medium } \\
\text { roughness tapered } \\
\text { diamond bur with a } \\
\text { rounded end (850/008; } \\
\text { JTC Fulldent SA) }\end{array}$ & $\begin{array}{l}\text { Impression } \\
\text { compound }\end{array}$ \\
\hline
\end{tabular}

conventional chamfer provides a good support for ceramic crown but it is not as good as deep chamfer and the deep chamfer is not also as good as a shoulder. The study that were done by Jalalian et al. ${ }^{14}$ also used chamfer and shoulder finish lines. These finish lines have a strong fracture resistance. The fracture resistance is stronger than biting forces so that we could use both of the finish lines. Chamfer finish line has a better fracture resistance than shoulder, and it is recommended to improve biomechanical performance of crown.

Taha et al. ${ }^{12}$ using shoulder as finish line for all-ceramic crowns. That statement supported Shillingburg et al. ${ }^{13}$

all-ceramic crowns. That statement supported Shillingburg et al. ${ }^{13}$ that the classic shoulder was the choice for all-ceramic crowns since long time ago. This type of finish line, it generates space for healthy restoration contours and maximum esthetics but it required more destruction of tooth structure compared with any other finish line. A better strength was given by shoulder finish line compared with chamfer finish line in all-ceramic crowns.

The other side, Vigolo et al. ${ }^{10}$ study were using zirconia with comparing two different finish line, which is rounded shoulder and shoulder-less/ knife-edge.
The results of this study supported the null hypothesis that there is no statically different between those two finish line. The limitation of study by Vigolo et al. ${ }^{10}$ is the small number samples. It was concluded that marginal fit of zirconia crowns between vertical and horizontal finish line was similar. This result also supported Poggio et al. ${ }^{15}$ study that for zirconia crowns, knifeedge margins allow clinical performance similar with the other margin designs, thereby requiring less removal of tooth structure.

Tsiagali et al. ${ }^{4}$ were using all-metal crown with chamfer finish line. In this studies, 60 intact maxillary premolar were used because the most frequently fractured cusps were mandibular first molars and maxillary first premolars. That result supported Shillingburg et al. ${ }^{13}$ statement, that shoulder finish line generally is not used as a finish line for cast metal restorations. A finish line is needed to enable the fabrication of a restoration with a good fit, and chamfer finish line is the best for providing the bulk needed for strength while still allowing good adaptation. ${ }^{16}$

\section{Conclusion}

From this systematic, it was concluded that in allmetal and all-ceramic crown, chamfer finish line were mostly used, but in zirconia crown, both 
rounded shoulder and shoulder-less/knife-edge were equally used. Unfortunately, articles that included in this review were so limited, therefore, future studies with more sample are needed to find a more accurate result.

\section{Acknowledgment}

The author would like to thanks to Faculty of Dentistry, Hasanuddin University, Makassar for support in processing the article.

\section{Conflict of Interest}

The authors report no conflict of interest.

\section{References}

1. Hey J, Schweyen R, Kupfer P, et al. Influence of preparation design on the quality of tooth preparation in preclinical dental education. J Dent Sci 2017;12: 27-32.

2. Machmud E. The design of fixed denture preparations affects the health of the periodontal tissue. J Dentomaxillofac Sci 2008; 7: 13-18. (In Indonesia)

3. Jalalian E, Zarbakhsh A, Mohtashamrad Z, et al. In Vitro effect of porcelain firing cycle and different thicknesses of IPS E.max CAD Core on marginal accuracy of allceramic restorations. J Dent (Tehran) 2015;12: 815-822.

4. Tsiagali V, Kirmanidou Y, Pissiotis A, et al. In Vitro assessment of retention and resistance failure loads of teeth restored with a complete coverage restoration and different core materials. J Prosthodont 2017;0: 1-8.

5. McCracken MS, Louis DR, Litaker MS, et al. Impression techniques used for single-unit crowns: findings from the national dental practice-based research network. J Prosthodont 2017;0: 1-11.

6. Srilekha M, Abirami G. Awareness of different types of finish lines of tooth preparation among working dental students- A questionnaire based study. J Pharm Sci Res 2016;8: 1210-1211.
7. Agustín-Panadero R, Solá-Ruíz MF, Chust C, et al. Fixed dental prostheses with vertical tooth preparations without finish lines: a report of two patients. J Prosthet Dent 2016;115: 520-526.

8. Liberati A, Altman DG, Tetzlaff J, et al. The PRISMA statement for reporting systematic reviews and metaanalyses of studies that evaluate health care interventions: Explanation and elaboration. PLoS Med 2009;6: 1-25.

9. Wallace BC, Kuiper J, Sharma A, et al. Extracting PICO sentences from clinical trial reports using supervised distant supervision. J Mach Learn Res 2016;17: 1-25.

10. Vigolo P, Mutinelli S, Biscaro L, et al. An in vivo evaluation of the fit of zirconium-oxide based, ceramic single crowns with vertical and horizontal finish line preparations. J Prosthodont 2015;24: 603-609.

11. Akin A, Toksavul S, Toman M. Clinical marginal and internal adaptation of maxillary anterior single all-ceramic crowns and 2-year randomized controlled clinical trial. J Prosthodont 2015;24: 345-350.

12. Taha D, Spintzyk S, Schille C, et al. Fracture resistance and failure modes of polymer infiltrated ceramic endocrown restorations with variations in margin design and occlusal thickness. J Prosthodont Res 2018;62: 293-297.

13. Shillingburg HT, Sather DA, Wilson EL, et al. Fundamentals of fixed prosthodontics. 4th Ed. Oklahoma: Quintessence Publishing Co, Inc; 2012.

14. Jalalian E, Aletaha NS. The effect of two marginal designs (chamfer and shoulder) on the fracture resistance of all ceramic restorations, inceram: an in vitro study. J Prosthodont Res 2011;55: 121-125.

15. Poggio CE, Dosoli R, Ercoli C. A retrospective analysis of 102 zirconia single crowns with knife-edge margins. J Prosthet Dent 2012;107: 317-321.

16. Jubhari EH, Machmud E, Hasminar, et al. The effect of fabrication techniques of temporary crowns on the gingiva health. J Dentomaxillofac Sci 2019;4: 133-136.

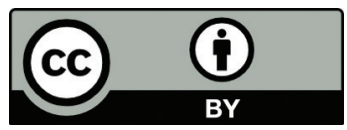

This work is licensed under a Creative Commons Attribution 